\title{
Speech-perception-in-noise and bilateral spatial abilities in adults with delayed sequential cochlear implantation
}

\author{
I Oosthuizen, D Swanepoel, C van Dijk \\ Department of Communication Pathology, University of Pretoria \\ Ilze Oosthuizen
}

Department of Communication Pathology, University of Pretoria; Callier Center, School of Behavioral \& Brain Sciences, University of Texas, Dallas, Texas, USA; Ear Science Institute Australia, Subiaco, Australia, and Ear Sciences Centre, School of Surgery, University of Western Australia, Nedlands, Australia

De Wet Swanepoel

Department of Communication Pathology, University of Pretoria

Catherine van Dijk

Corresponding author: D Swanepoel (dewet.swanepoel@up.ac.za)

\begin{abstract}
Objective. To determine speech-perception-in-noise (with speech and noise spatially distinct and coincident) and bilateral spatial benefits of head-shadow effect, summation, squelch and spatial release of masking in adults with delayed sequential cochlear implants.

Study design. A cross-sectional one group post-test-only exploratory design was employed. Eleven adults (mean age 47 years; range 21 - 69 years) of the Pretoria Cochlear Implant Programme (PCIP) in South Africa with a bilateral severe-to-profound sensorineural hearing loss were recruited. Prerecorded Everyday Speech Sentences of The Central Institute for the Deaf (CID) were used to evaluate participants' speech-in-noise perception at sentence level. An adaptive procedure was used to determine the signal-to-noise ratio (SNR, in dB) at which the participant's speech reception threshold (SRT) was achieved. Specific calculations were used to estimate bilateral spatial benefit effects.

Results. A minimal bilateral benefit for speech-in-noise perception was observed with noise directed to the first implant (CI 1) (1.69 dB) and in the speech and noise spatial listening condition $(0.78 \mathrm{~dB})$, but was not statistically significant. The head-shadow effect at $180^{\circ}$ was the most robust bilateral spatial benefit. An improvement in speech perception in spatially distinct speech and noise indicates the contribution of the second implant (CI 2) is greater than that of the first implant (CI 1) for bilateral spatial benefit.

Conclusion. Bilateral benefit for delayed sequentially implanted adults is less than previously reported for simultaneous and sequentially implanted adults. Delayed sequential implantation benefit seems to relate to the availability of the ear with the most favourable SNR.
\end{abstract}

Keywords: bilateral benefit, cochlear implant, head-shadow effect, sequential implantation, speech-in-noise perception, squelch, summation

S Afr J CD 2012;59(1):45-52. DOI:10.7196/SAJCD.133

Cochlear implants (CIs) are widely recognised as the most successful sensory prosthetic device in the medical world (Wolfe \& Schafer, 2010). The widespread success has led to bilateral cochlear implantation becoming accepted medical practice in clinically suitable adults and children. The recent bilateral cochlear implantation position statement underscores the importance of bilateral implantation to enhance bilateral processing benefits for users (Balkany et al., 2008). The advantages of binaural hearing may include a range of benefits such as improved listening or speech recognition in quiet and in noise, localisation, directional hearing, and bilateral spatial benefits, such as head-shadow effect, summation, and squelch (Litovsky et al., 2004; Cochlear Corporation Limited, 2005; Litovsky, Parkinson, Arcaroli \& Sammeth, 2006; Neuman, Haravon, Sislian \& Waltzman, 2007).

The head-shadow effect is the strongest and most robust bilateral benefit effect demonstrated for spatially separated speech-in-noise tests (Laszig et al., 2004; Litovsky et al., 2006). In implanted adults, head-shadow effects of 3 - $11 \mathrm{~dB}$ have been demonstrated (Gantz et al., 2002; Laszig et al., 2004). Improved speech understanding in noise can be attributed to a second bilateral spatial benefit effect, namely the binaural summation effect. The latter can improve speech perception scores up to $19 \%$ in quiet and up to $16 \%$ in noise (Tyler et al., 2002). Summation effects previously reported vary in effect sizes of up to $6 \mathrm{~dB}$ in some users and no effect or negative effects in others (Gantz et al., 2002; Laszig et al., 2004; Litovsky et al., 2006; Wolfe et al., 2007). The squelch effect is another possible advantage of bilateral hearing through bilateral cochlear implantation. It is a modest bilateral benefit with effects up to $2 \mathrm{~dB}$, although some reports indicate no effect or even negative effects (Gantz et al., 2002; Laszig et al., 2004; Litovsky et al., 2006).
Bilateral implantation can be divided into the following categories: (i) simultaneous implantation where both ears are implanted during the same surgical procedure; (ii) sequential implantation with interimplant intervals between 6 and 12 months on average; and (iii) delayed sequential implantation with inter-implant intervals of more than 2 years (Manrique, Huarte, Valdivieso \& Pérez, 2007; Peters, Litovsky, Parkinson \& Lake, 2007). In the South African context simultaneous implantation is not yet routinely employed. Of all the patients of the Pretoria Cochlear Implant Programme (PCIP) only 13\% have received bilateral cochlear implants (BiCIs), all of which were sequentially implanted. The Tygerberg programme is the only programme that has three simultaneously implanted adults (A. M. U. Muller, personal communication, 17 November 2010). There are several reasons why patients in the South African context receive sequential CIs, among others: limited reimbursement or financial resources to fund simultaneous implantation surgery; additional risk and difficulty of extended surgical procedures; the practice of preserving one ear for future technologies; difficulty in obtaining collaboration from medical insurance providers/medical aid funds for simultaneous bilateral implantation; and extended time needed for mapping two implants at the same time, which could lead to fatigue, especially in young children (Laszig et al., 2004; Litovsky et al., 2006).

There are limited data on bilateral benefits of delayed sequentially implanted adults in previous studies. This might suggest that this population may not benefit from bilateral processing, such as sound localisation and speech-in-noise perception. It is clear from previous studies of bilateral implantation in adults that more robust improvements in speech-in-noise perception are typical of simultaneous-implant CI 
users (Tyler et al., 2002; Cochlear Corporation Limited, 2005; Ramsden, et al., 2005; Litovsky et al., 2006). Galvin and colleagues (2010) aimed to determine if adolescents ( $\geq 10$ years of age) gained additional perceptual benefit from sequential bilateral CIs within 12 months. The results indicated that adolescents may gain additional benefit from a second cochlear implant (CI 2) regarding bilateral perception, even if their hearing loss is congenital and it is more than 16 years since the receipt of their first cochlear implant (CI 1). Tyler, Dunn, Witt and Noble (2007) found that sequentially implanted adults received significant bilateral improvement on at least one speech-perception test compared with either implant alone. They concluded that sequential implants can be beneficial for adults even after many years of monaural use and even with very different CIs. However, although Ramsden et al. (2005) reported a significant bilateral benefit for speech perception in quiet and in noise for sequentially implanted adults, it was concluded that sequential implantation with long delays between resulted in poor second-ear performance for some individuals and has limited the extent of bilateral processing benefit that can be obtained by these users. Litovsky et al. (2006) found that all simultaneously implanted patients showed significant bilateral processing benefit on at least one of the speech-perception-in-noise measures, and the strongest bilateral benefit was measured for the head-shadow effect. Some individuals with simultaneously implanted CIs showed evidence of binaural squelch and summation (Litovksy et al., 2006).
It is possible that early second cochlear implantation for adults with sequential cochlear implantation might allow better acquisition of bilateral processing and bilateral spatial hearing, thus leading to improved speechperception-in-noise performance (Litovsky et al., 2006). Previous studies did not routinely determine which $\mathrm{CI}$ was the superior functioning implant (Cochlear Corporation Limited, 2005). It would appear that delayed sequential cochlear implantation could affect the extent of the experience of bilateral processing benefit in terms of speech-in-noise perception, especially spatially coincident speech and noise signals. Bilateral implantation for adults in South Africa currently occurs predominantly in a delayed sequential time frame. Consequently, the question is how well these delayed sequentially implanted users are able to perceive speech in noise.

The main aim of this study therefore was to determine the bilateral speech-perception-in-noise benefit in a group of delayed sequentially implanted adults. The following sub-aims were identified in order to attain the main aim:

- To determine the speech-perception-in-noise ability (in spatially separated and spatially coincident speech and noise listening conditions)

- To calculate the bilateral spatial benefits (head-shadow effect, summation, squelch, and spatial release of masking (SRM)) using abovementioned results compared with normative data.

Table 1. Selection criteria for participants

Criterion

Clients with sequential bilateral cochlear implants (CIs)

Type of CI: All participants should be implanted with Nucleus CIs from Cochlear $^{\text {Tix }}$

Model of CI: Freedom, Nucleus 22 or Nucleus 24

Duration of time since implantation: Participants must already have been using their second cochlear implant (CI 2) for at least a period of 1 year

Participants' CIs were required to have been bilaterally balanced with the company's (Cochlear ${ }^{\mathrm{Tw}}$ ) software a month before the proposed test battery for data collection

Aided pure tone thresholds (air conduction) between 25 and $40 \mathrm{~dB}$ HL and aided speech discrimination scores of $\geq 70 \%$

Type and degree of hearing loss (prior to implantation): Participants were required to have had a bilateral severe-to-profound (71 dB HL to $>90 \mathrm{~dB}$ $\mathrm{HL}$ ) or moderate-to-profound (41 dB HL to $>90 \mathrm{~dB} \mathrm{HL}$ ) sensorineural hearing loss (Clark, 1981 in Harrel, 2002) prior to the implant

Participants were required to be clients of the PCIP at the University of Pretoria

Language: Participants should be Afrikaans and/or English speaking

Ages: The participants were required to be 18 years or older

\section{Justification}

All clients should have been sequentially implanted (CIs implanted during separate surgeries) (Lustig \& Wackym, 2005) as the main aim of the study is to determine the bilateral processing benefits achieved in sequentially implanted CI users

To date, the Pretoria Cochlear Implant Programme (PCIP) only implants Nucleus products. This criterion ensured uniformity of the product, thus lessening variability of the outcomes

These three models are products from Cochlear ${ }^{\text {int }}$, with which the clients of PCIP are implanted. Other types of CI models such as double array implants were not included. This helped diminish variability of the outcomes of the study

The duration of at least 1 year's use is to ensure that the map for this implant would have been stabilised (Hughes et al., 2001). Furthermore, the participant must have had time to become adequately adjusted to his/her bilateral cochlear implantation status in terms of wearing and using both devices. According to the literature, adult CI users typically reach their performance plateau within 6 months to 1 year post-implantation (Teoh, Pisoni \& Miyamoto, 2004).

It is imperative to ensure even balance of the loudness of both devices, as sounds will lateralise to the louder ear if loudness is unbalanced (Cochlear Corporation Limited, 2005). To remove the influence of binaural loudness summation on performance as far as possible, Laszig et al. (2004) suggest that loudness balancing of unilaterally and bilaterally used processor programmes/ maps be required

Clients with aided thresholds greater than $40 \mathrm{~dB}$ HL and aided speech discrimination scores less than $70 \%$ may be viewed as not well adapted and thus not good CI users (Moore \& Teagle, 2002)

The participants' type and degree of hearing loss should correspond with candidacy criteria as accepted by the PCIP. These criteria are based on the selection criteria of Cochlear ${ }^{\mathrm{m}}$, where bilateral severe-to-profound or moderateto-profound sensorineural hearing loss is stated as first criterion for adults (Cochlear Corporation Limited, n.d.)

This ensured uniformity among participants. It was logistically more convenient for the researcher to conduct the fieldwork at the PCIP as she had access to the premises as well as to clients' records. The relevant information was therefore easily available and obtainable

The participants must be able to participate in the required test battery. The majority of bilaterally implanted clients of the PCIP are either English or Afrikaans speaking. The researcher is also only proficient in these two languages. This ensured clear communication during informed consent and the course of fieldwork

The study aimed to investigate the adult population of the PCIP and this criterion also ensured that informed consent could be obtained from the participants themselves 
Table 2. Description of research participants

\begin{tabular}{|c|c|c|c|c|c|c|c|c|c|}
\hline No. & $\begin{array}{l}\text { Age at test } \\
\text { (years) }\end{array}$ & $\begin{array}{l}\text { Age at } \\
\text { HL onset } \\
\text { (years) }\end{array}$ & $\begin{array}{l}\text { Likely HL } \\
\text { aetiology }\end{array}$ & $\begin{array}{l}\text { CI } 1 \text { switch- } \\
\text { on age } \\
\text { (years) }\end{array}$ & CI 1 description & $\begin{array}{l}\text { CI } 2 \text { switch- } \\
\text { on age } \\
\text { (years) }\end{array}$ & CI 2 description & $\begin{array}{l}\text { CI } 1 \text { and } \\
\text { CI } 2 \\
\text { interval } \\
\text { (years) }\end{array}$ & $\begin{array}{l}\text { Duration } \\
\text { of BiCI use } \\
\text { (years) }\end{array}$ \\
\hline 1 & 59.5 & 5 & $\begin{array}{l}\text { Chronic otitis } \\
\text { media }\end{array}$ & 51.8 & $\begin{array}{l}\text { Nucleus } 24 \mathrm{M} \\
\text { Freedom }\end{array}$ & 54.1 & $\begin{array}{l}\text { Nucleus } 24 \text { CA } \\
\text { Freedom }\end{array}$ & 2.5 & 5.4 \\
\hline 2 & 69.10 & 9 & Mumps & 59.2 & $\begin{array}{l}\text { Nucleus 24M } \\
\text { Esprit 3G }\end{array}$ & 64.5 & $\begin{array}{l}\text { Nucleus 24CA } \\
\text { Esprit 3G }\end{array}$ & 5.3 & 5.5 \\
\hline 3 & 66.8 & 28 & Progressive & 61.10 & $\begin{array}{l}\text { Freedom 24CA } \\
\text { Freedom }\end{array}$ & 64.6 & $\begin{array}{l}\text { Freedom } 24 \mathrm{CA} \\
\text { Esprit } 3 \mathrm{G}\end{array}$ & 2.8 & 2.2 \\
\hline 4 & 66.3 & 31 & Progressive & 55.9 & $\begin{array}{l}\text { Nucleus 24M } \\
\text { Freedom }\end{array}$ & 61.7 & $\begin{array}{l}\text { Freedom 24CA } \\
\text { Freedom }\end{array}$ & 5.10 & 4.8 \\
\hline 5 & 60.3 & 35 & Progressive & 45.10 & $\begin{array}{l}\text { Nucleus 22M } \\
\text { Freedom }\end{array}$ & 56.4 & $\begin{array}{l}\text { Freedom } 24 \mathrm{CA} \\
\text { Nucleus } 5\end{array}$ & 10.6 & 3.11 \\
\hline 6 & 23 & 0 & $\begin{array}{l}\text { Extreme } \\
\text { prematurity \& } \\
\text { complications }\end{array}$ & 19.5 & $\begin{array}{l}\text { Freedom 24CA } \\
\text { Nucleus } 5\end{array}$ & 21.11 & $\begin{array}{l}\text { Freedom 24CA } \\
\text { Freedom }\end{array}$ & 1.4 & 2 \\
\hline 7 & 21.10 & 2 & Meningitis & 4.6 & $\begin{array}{l}\text { Nucleus } 22 \\
\text { Freedom }\end{array}$ & 16.6 & $\begin{array}{l}\text { Nucleus } 24 \mathrm{CA} \\
\text { Freedom }\end{array}$ & 12 & 5.4 \\
\hline 8 & 54.3 & 13 & Progressive & 47.7 & $\begin{array}{l}\text { Nucleus } 24 \\
\text { Freedom }\end{array}$ & 49.1 & $\begin{array}{l}\text { Nucleus 24CA } \\
\text { Esprit 3G }\end{array}$ & 1.6 & 5.2 \\
\hline 9 & 32.6 & 0 & Genetic & 23.11 & $\begin{array}{l}\text { Nucleus } 24 \mathrm{~K} \\
\text { Nucleus } 5\end{array}$ & 29.6 & $\begin{array}{l}\text { Freedom } 24 \mathrm{CA} \\
\text { Freedom }\end{array}$ & 4.7 & 4.1 \\
\hline 10 & 44.6 & 22 & $\begin{array}{l}\text { Post-traumatic } \\
\text { MVA }\end{array}$ & 39.8 & $\begin{array}{l}\text { Nucleus 24CA } \\
\text { Freedom }\end{array}$ & 41.4 & $\begin{array}{l}\text { Freedom } 24 \mathrm{CA} \\
\text { Freedom }\end{array}$ & 2.8 & 3.2 \\
\hline 11 & 20.11 & 0 & Congenital & 7.1 & $\begin{array}{l}\text { Nucleus 22M } \\
\text { Esprit 3G }\end{array}$ & 17 & $\begin{array}{l}\text { Freedom } 24 \mathrm{CA} \\
\text { Freedom }\end{array}$ & 9.11 & 3.11 \\
\hline
\end{tabular}

\section{Materials and methods}

The study objective was to assess the speech-perception-in-noise abilities (with speech and noise spatially distinct and coincident) as well as bilateral spatial benefits (head-shadow effect, summation, squelch and SRM) in adults with delayed sequential cochlear implantation. This study was approved by the institutional review board before any data collection commenced.

\section{Participants}

Eleven adult patients of the PCIP were recruited, with a bilateral severe-toprofound sensorineural hearing loss, sequentially implanted with systems from Cochlear ${ }^{\text {rn }}$ with at least 1 year of bilateral use and recently mapped and balanced in terms of loudness between the implants. Ten participants' first language was Afrikaans. Only one participant spoke English as first language. The participant selection criteria are provided in Table 1.

Hearing loss aetiology was determined from medical records. Participant ages ranged from 21 to 69 years at the time of testing (mean 47 years) with age at first and second switch-on ranging from 4.6 to 61.1 years (mean 37.7 years) and 16.6 to 64.6 years (mean 43.3 years) respectively (Table 2). Duration between the CI 1 and CI 2's switch-on ranged from 16 months (1 year 4 months) to 12 years (mean duration 4.3 years). The duration of bilateral implant use ranged from 24 months to 54 months (mean duration: 49 months). Most participants $(9 / 11)$ can be considered as late implanted with unfavourable interval periods ( $>2-5$ years).

\section{Materials and methods}

An audiometric booth, certified annually, was used to provide a soundtreated environment during testing. This was to ensure accurate and reliable pure tone and speech measurements. Speech and noise were presented from separate loudspeakers with an angular separation of $90^{\circ}$ between the speakers (Figures 1 - 3). Speech was always presented from the front and noise was presented from a different loudspeaker in order to direct the noise to the participant's right and then his/her left ear. For spatially coincident speech and noise, speech and noise were presented from a single loudspeaker in front of the participant.

Pre-recorded Everyday Speech Sentences of the Institute for the Deaf (CID) were used to evaluate the participants' speech-in-noise perception at sentence level (Alpiner \& McCarthy, 2000). The Afrikaans translated version of these sentences, by Muller and De Stadler (1987) was used for the 10 Afrikaans-speaking participants. Before presentation of each sentence list, a calibration tone was presented in order for the researcher to monitor the volume unit (VU) meter of the audiometer to ensure that the audiometer presented the recorded speech material at the specified level (Wilber, 2002).Sentences were presented through the specified loudspeaker as a closed set. Participants were instructed to repeat each sentence as it was presented and no feedback as to correct or incorrect response was provided. Continuous speech noise was selected, and presented simultaneously with the sentences at a fixed level of $55 \mathrm{~dB}$ HL. An adaptive procedure was used to determine the signal-to-noise ratio $(\mathrm{SNR}$, in $\mathrm{dB})$ at which the participant's speech reception threshold (SRT) was achieved, thus the level where the participant achieved at least $50 \%$ performance. In this process the first sentence was presented at $0 \mathrm{~dB}$ SNR, i.e. speech and noise presented at $55 \mathrm{~dB}$ HL. The speech signal level of the first sentence was increased in steps of $2 \mathrm{~dB}$ until the participant could identify the first sentence correctly, based on the number of correct keywords. Subsequently, the remaining sentences were presented adaptively in a one-up, one-down method with a $2 \mathrm{~dB}$ 


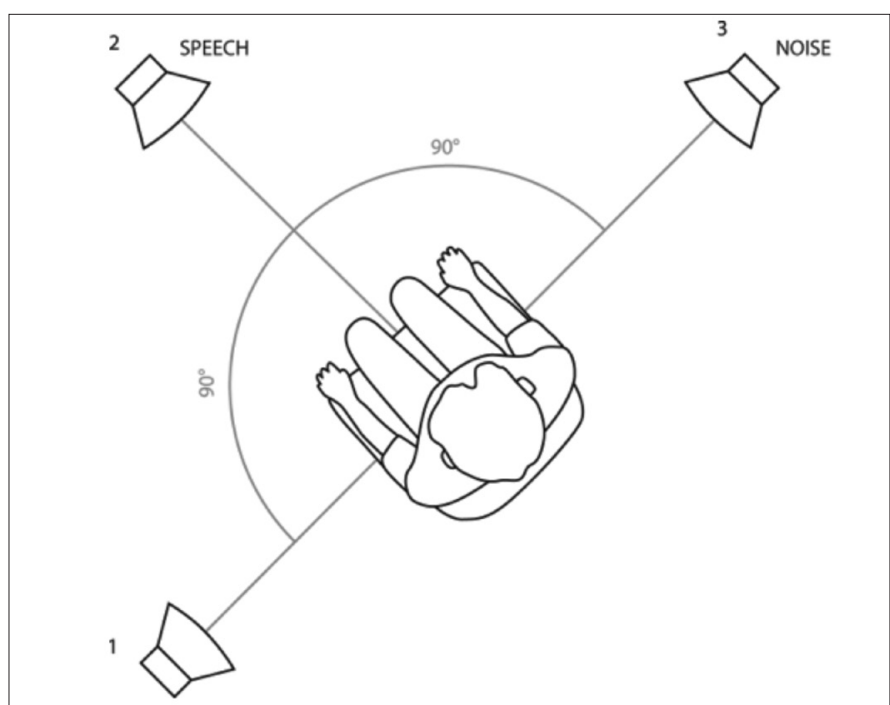

Fig. 1. Test set-up to determine speech-perception-in-noise abilities: speech and noise spatially separated with noise directed to the right ear. Speech was presented from the front loudspeaker (numbered 2) and noise was presented from the loudspeaker on the participant's right-hand side (numbered 3).



Fig. 2. Test set-up to determine speech-perception-in-noise abilities: speech and noise spatially separated with noise directed to the left ear. Speech was presented from the front loudspeaker (numbered 3) and noise was presented from the loudspeaker on the participant's left-hand side (numbered 2).

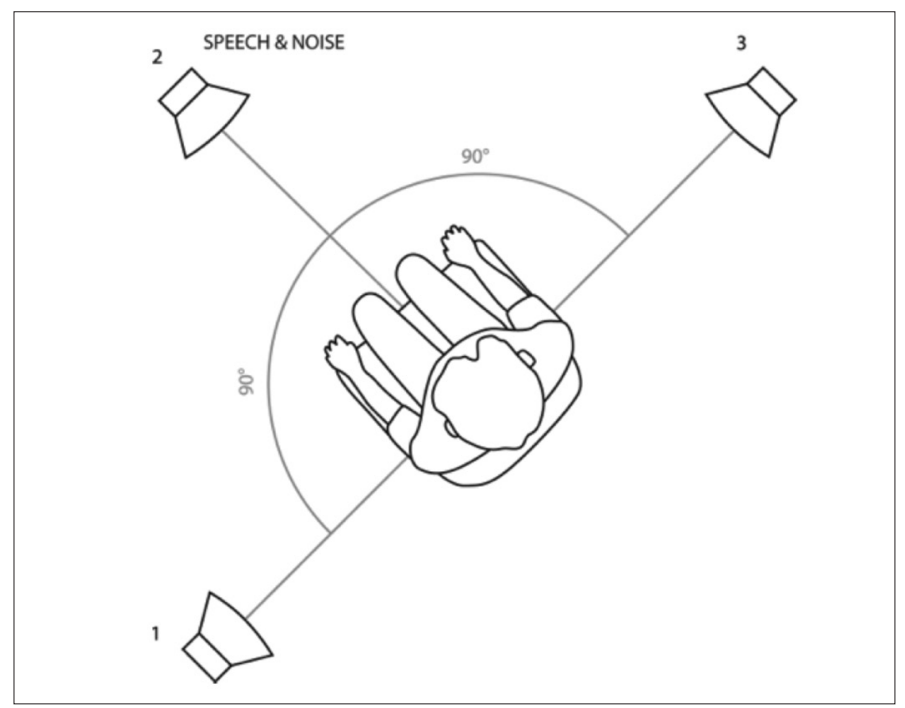

Fig. 3. Test set-up to determine speech-perception-in-noise abilities: speech and noise spatially coincident. Speech and noise were presented simultaneously from the loudspeaker directly in front of the participant (numbered 2). step size. The test result was the average SNR of the last six presentation levels. The measures for spatially separated speech and noise were conducted with the noise directed to the participant's right ear (NR), with only the CI 1 switched on, then with CI 2 switched on and finally with both implants switched on at once (BiCI). Subsequently the noise was directed to the participant's left ear (NL) and then together with the speech from the front loudspeaker following the same procedure as for the NR condition. Thus, there were nine possible listening configurations. However, results for spatially separated speech and noise were discussed in terms of noise ipsilateral to the CI 1 and noise ipsilateral to the CI 2.

To estimate the bilateral spatial benefit, i.e. the effects of head shadow, summation, squelch and SRM, the following calculations were used (Van Deun, Van Wieringen \& Wouters, 2010):

Head shadow $90^{\circ}$ - the head-shadow effect arising from a shift in the noise position of $90^{\circ}$ - was calculated as the difference in the SRT value (in $\mathrm{dB}$ ) obtained with the left/right ear in the noise from the front (NF) versus NR/NL condition.

Head shadow $180^{\circ}$ - this head-shadow effect was calculated as the difference in the SRT value (in $\mathrm{dB}$ ) obtained with the left/right ear in the NL/NR versus NR/NL condition when there was a $180^{\circ}$ change in the noise position.

Squelch - this is the enhancement in speech perception owing to the addition of an ear with a poorer SNR. It was calculated as the difference between the SRT values (in $\mathrm{dB}$ ) for the left/right ear and both implants in the NR/NL condition.

Summation - summation is produced by binaural redundancy (also known as diotic summation), that is the difference between bilateral and better ear performance in spatially coincident speech and noise (Schön, Müller \& Helms, 2002). Subsequently, summation was calculated as the difference between the SRT values (in $\mathrm{dB}$ ) of the CI 1/CI 2 and BiCIs in the NF condition.

Spatial release of masking (SRM) - this is the improvement in speech perception as a result of spatial separation of speech and noise when listening with both ears. Hence, SRM was determined as the difference in bilateral SRT values (in $\mathrm{dB}$ ) in the NF versus NR or NL condition. In support of the SRM effect, the benefit of adding the better SNR ear was determined. This implies the improvement in speech perception resulting from the addition of an ear with a better SNR. Thus, the difference between the SRT value for the left/right ear and the bilateral SRT in the NL/NR conditions was determined. This could possibly include all of the abovementioned spatial benefits because an ear is added in a situation with spatially distinct speech and noise.

Quantitative methods were utilised to analyse and process data electronically by means of a statistical software package (SPSS) (Field, 2005). Descriptive comparisons were made and the Mann-Whitney U-test was used to draw conclusions about the sample population on a 5\% level of significance. The Mann-Whitney U-test is a distributionfree test and was selected because of the small sample size (Steyn, Smit, du Toit \& Strasheim, 2003; Miller \& Miller, 2004).

\section{Reliability and validity}

To increase reliability as far as possible the following steps were implemented:

- Each participant was contacted personally, telephonically or via electronic mail to explain the purpose of the study to them and to obtain their consent to participate.

- A qualified and registered audiologist performed the measurements.

- A qualified service technician was involved to verify the use of the correct equipment and test set-up.

- Sound level measurements of the intensity of the signals to be presented in sound field were done before commencement of the 
testing procedures to ensure that the signals were presented at the specific intensity for each of the tests.

- A specific test set-up was used for each participant with marked places for the participant and speakers, according to recent literature (Cochlear Corporation Limited, 2005).

- The clinical audiometer that was used was calibrated to ensure accurate measurements. The Calibration Standard of the International Standards Organisation (OSI) is accepted in South Africa.

- Recorded CID sentence test material was used for the speech-innoise tests, to further enhance reliability and to avoid the presenting variability of using live voice. Furthermore, the possibility of using speech reading or lip reading by participants to support their speech perception was eliminated by the use of recorded sentence test material which increased the reliability even more.

To increase internal and external validity the following strategies were employed. Before the test battery was conducted, each participant's CI was mapped and balanced to ensure optimal functioning for the testing procedures. The same audiologist conducted the same measurements for each participant. All participants received the same information regarding the purpose of the study and their role during the study, as well as identical instructions during the measurements. During the tests, participants used the programme on their processors that they use for general listening in order to obtain a reflection of their everyday functioning. As the PCIP only has a small population of sequentially bilateral implanted adults, the purposive convenient sampling method and selection criteria were vigorously implemented to select a representative sample of sequentially implanted adult clients of the PCIP (Leedy \& Ormrod, 2005).

\section{Results and analysis \\ Speech-in-noise perception}

Tables 3 and 4 illustrate the SNR values for CI 1, CI 2, the superior performing implant and both implants (BiCI) in the spatially distinct speech and noise conditions and in the spatially coincident speech and noise conditions, respectively. From Table 3 it is clear that in the unilateral listening conditions a performance advantage for the ear opposite the noise source was evident in 91\% $(n=10 / 11)$ and $55 \%(n=6 / 11)$ of participants with noise directed to CI 1 and CI 2, respectively. Table 4 indicates that CI 2 was the superior performing implant for speech-in-noise perception with speech and noise being coincident for the majority of participants $(n=9 / 11)$.
Figure 4 and Table 3 demonstrate that with noise directed to CI 1 and CI $2,64 \%(n=7 / 11)$ and $36 \%(n=4 / 11)$ of participants respectively demonstrated bilateral benefit during speech perception in spatially separated speech and noise. In contrast, with noise directed to CI 27 participants did not show a bilateral benefit but achieved a better SNR value with their superior implant only (Table 3). For 4 of these 7 participants (participants 1, 5, 6 and 7) their CI 1 remained superior in comparison to their performance with bilateral implant use. An average SNR value of $19.43 \mathrm{~dB}$ and $17.74 \mathrm{~dB}$ was achieved respectively for the best performing $\mathrm{CI}$ and the bilateral listening condition with noise on $\mathrm{CI}$ 1. An average SNR of $19.73 \mathrm{~dB}$ and $20.03 \mathrm{~dB}$ was achieved respectively for the best performing $\mathrm{CI}$ and the bilateral listening condition with noise on CI 2. Thus, a bilateral benefit was present only when noise was directed to $\mathrm{CI} 1$ and indicated an average improvement of $1.69 \mathrm{~dB}$. As displayed in Figure $4,36 \%$ of participants $(n=4 / 11)(1,5,8$ and 10$)$ achieved bilateral

\begin{tabular}{|c|c|c|c|c|}
\hline \multirow[t]{2}{*}{ Participant } & \multicolumn{4}{|c|}{ SPIN with speech and noise presented from the front } \\
\hline & CI 1 & CI 2 & Superior CI & $\mathrm{BiCI}$ \\
\hline 1 & $20 \mathrm{~dB}$ & $18 \mathrm{~dB}$ & CI 2 & $17.67 \mathrm{~dB}^{*}$ \\
\hline 2 & $23 \mathrm{~dB}$ & $22.33 \mathrm{~dB}$ & CI 2 & $22.67 \mathrm{~dB}$ \\
\hline 3 & $18.67 \mathrm{~dB}$ & $9.67 \mathrm{~dB}$ & CI 2 & $12.33 \mathrm{~dB}$ \\
\hline 4 & $23 \mathrm{~dB}$ & $20 \mathrm{~dB}$ & CI 2 & $20.67 \mathrm{~dB}$ \\
\hline 5 & $22 \mathrm{~dB}$ & $22.67 \mathrm{~dB}$ & CI 1 & $18.33 \mathrm{~dB}^{*}$ \\
\hline 6 & $22.67 \mathrm{~dB}$ & $22 \mathrm{~dB}$ & CI 2 & $22.33 \mathrm{~dB}$ \\
\hline 7 & $18.33 \mathrm{~dB}$ & $22.67 \mathrm{~dB}$ & CI 1 & $20.33 \mathrm{~dB}$ \\
\hline 8 & $20.67 \mathrm{~dB}$ & $20 \mathrm{~dB}$ & CI 2 & $15 \mathrm{~dB}^{*}$ \\
\hline 9 & $22.33 \mathrm{~dB}$ & $21.67 \mathrm{~dB}$ & CI 2 & $22 \mathrm{~dB}$ \\
\hline 10 & $18.33 \mathrm{~dB}$ & $16.33 \mathrm{~dB}$ & CI 2 & $12.33 \mathrm{~dB}^{*}$ \\
\hline 11 & $23 \mathrm{~dB}$ & $20.33 \mathrm{~dB}$ & CI 2 & $22.33 \mathrm{~dB}$ \\
\hline Average & $21.06 \mathrm{~dB}$ & $19.61 \mathrm{~dB}$ & $19.15 \mathrm{~dB}$ & $18.37 \mathrm{~dB}$ \\
\hline \multicolumn{5}{|c|}{$\begin{array}{l}\text { * Indicates bilateral benefit achieved (thus, perceive speech at lower SNR compared } \\
\text { with superior implant). }\end{array}$} \\
\hline \multicolumn{5}{|c|}{$\begin{array}{l}\text { SNR = signal-to-noise ratio; } \mathrm{CI} 1=\text { first cochlear implant; } \mathrm{CI} 2=\text { second cochlear } \\
\text { implant; SPIN = speech-perception-in-noise ability; } \mathrm{BiCI}=\text { both cochlear implants. }\end{array}$} \\
\hline
\end{tabular}

Table 3. SNR values for CI 1, CI 2, superior implant and bilateral implant condition in spatially separated speech and noise $(N=11)$

\begin{tabular}{|c|c|c|c|c|c|c|c|c|}
\hline & \multicolumn{4}{|c|}{ SPIN with noise on CI 1} & \multicolumn{4}{|c|}{ SPIN with noise on CI 2} \\
\hline & CI 1 & CI 2 & Superior CI & $\mathrm{BiCI}$ & CI 1 & CI 2 & Superior CI & $\mathrm{BiCI}$ \\
\hline 1 & $24.67 \mathrm{~dB}$ & $17 \mathrm{~dB}$ & CI 2 & $15 \mathrm{~dB}^{\star}$ & $20.33 \mathrm{~dB}$ & $27.6 \mathrm{~dB}$ & CI 1 & $23 \mathrm{~dB}$ \\
\hline 2 & $29 \mathrm{~dB}$ & $28.67 \mathrm{~dB}$ & CI 2 & $28 \mathrm{~dB}^{*}$ & $28.67 \mathrm{~dB}$ & $28 \mathrm{~dB}$ & CI 2 & $28.33 \mathrm{~dB}$ \\
\hline 3 & $26.67 \mathrm{~dB}$ & $9.67 \mathrm{~dB}$ & CI 2 & $3.67 \mathrm{~dB}^{*}$ & $21.67 \mathrm{~dB}$ & $17 \mathrm{~dB}$ & CI 2 & $16.33 \mathrm{~dB}^{*}$ \\
\hline 4 & $29 \mathrm{~dB}$ & $13 \mathrm{~dB}$ & CI 2 & $14.33 \mathrm{~dB}$ & $28.33 \mathrm{~dB}$ & $20.33 \mathrm{~dB}$ & CI 2 & $24.33 \mathrm{~dB}$ \\
\hline 5 & $28.67 \mathrm{~dB}$ & $23 \mathrm{~dB}$ & CI 2 & $14.33 \mathrm{~dB}^{*}$ & $17.67 \mathrm{~dB}$ & $24.67 \mathrm{~dB}$ & CI 1 & $18.33 \mathrm{~dB}$ \\
\hline 6 & $27.33 \mathrm{~dB}$ & $26 \mathrm{~dB}$ & CI 2 & $22 \mathrm{~dB}^{*}$ & $18.33 \mathrm{~dB}$ & $27.67 \mathrm{~dB}$ & CI 1 & $22.33 \mathrm{~dB}$ \\
\hline 7 & $19 \mathrm{~dB}$ & $20.33 \mathrm{~dB}$ & CI 1 & $23 \mathrm{~dB}$ & $9 \mathrm{~dB}$ & $26 \mathrm{~dB}$ & CI 1 & $17.67 \mathrm{~dB}$ \\
\hline 8 & $21.33 \mathrm{~dB}$ & $9 \mathrm{~dB}$ & CI 2 & $9 \mathrm{~dB}$ & $20.33 \mathrm{~dB}$ & $25.67 \mathrm{~dB}$ & CI 1 & $20.33 \mathrm{~dB}$ \\
\hline 9 & $28.5 \mathrm{~dB}$ & $23.67 \mathrm{~dB}$ & CI 2 & $23 \mathrm{~dB}^{*}$ & $27.33 \mathrm{~dB}$ & $26.67 \mathrm{~dB}$ & CI 2 & $17 \mathrm{~dB}^{*}$ \\
\hline 10 & $19.67 \mathrm{~dB}$ & $19 \mathrm{~dB}$ & CI 2 & $14.33 \mathrm{~dB}^{*}$ & $13 \mathrm{~dB}$ & $24 \mathrm{~dB}$ & CI 1 & $9 \mathrm{~dB}^{*}$ \\
\hline 11 & $27.33 \mathrm{~dB}$ & $25.67 \mathrm{~dB}$ & CI 2 & $26.5 \mathrm{~dB}$ & $29 \mathrm{~dB}$ & $26.33 \mathrm{~dB}$ & CI 2 & $23.67 \mathrm{~dB}^{*}$ \\
\hline Mean & $25.56 \mathrm{~dB}$ & $19.55 \mathrm{~dB}$ & $19.43 \mathrm{~dB}$ & $17.74 \mathrm{~dB}$ & $21.24 \mathrm{~dB}$ & $24.91 \mathrm{~dB}$ & $19.73 \mathrm{~dB}$ & $20.03 \mathrm{~dB}$ \\
\hline
\end{tabular}


benefit when speech and noise were spatially coincident. The observation point 9 in Figure 4 emphasises the significantly better performance of participant 3 with his best performing implant, which was notably better than the other participants. A significant range of bilateral benefits in terms of SNR in dB was evident ( 15 - $22.67 \mathrm{~dB})$. An average SNR of 19.15 $\mathrm{dB}$ and $18.37 \mathrm{~dB}$ was respectively achieved for the best performing $\mathrm{CI}$ and the bilateral listening condition. No statistically significant bilateral benefit $(p>0.05)$ for speech perception in spatially separated speech and noise conditions ( $p=0.562$ for noise on CI 1 and $p=0.898$ for noise on CI 2 ) or spatially coincident speech and noise $(p=0.442)$ was found.

\section{Bilateral spatial benefits}

The spatial benefits effects sizes are listed in Table 5.

The median head-shadow effect at $90^{\circ}(0 \mathrm{~dB}$ for CI 1 and CI 2$)$ did not correspond significantly ( $p>0.05$ ) with the ideal range of $\geq 3 \mathrm{~dB}$ (Schön et al., 2002; Laszig et al., 2004; Litovsky et al., 2006). The median head-

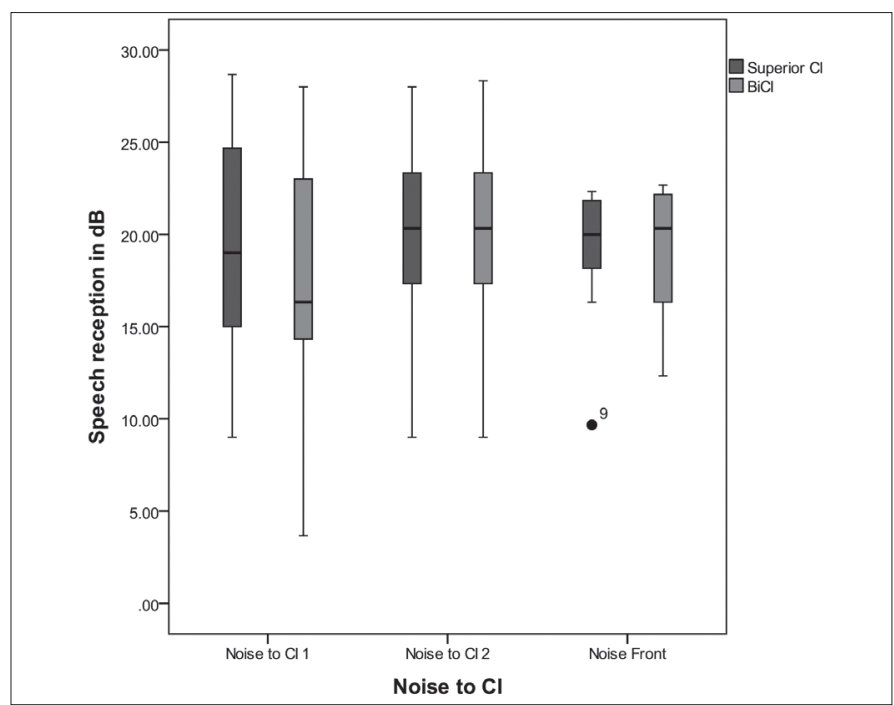

Fig. 4. Speech-in-noise perception for the superior performing implant compared with the bilateral implant condition $(\mathrm{N}=11)$. A bilateral benefit is achieved when the participant perceives speech at a lower speech reception (SR) value (in $\mathrm{dB}$ ) with both implants (light bars) compared with the SR value (in $d B$ ) of the superior performing implant (dark bars). Box plots represent the median (thick horizontal line), lower and upper quartiles (ends of boxes), minimum and maximum values (ends of whiskers) and extreme values (dark circles). shadow effect at $180^{\circ}$ for both CI $1(4 \mathrm{~dB})$ and CI $2(5 \mathrm{~dB})$ fell within the accepted range $(\geq 3 \mathrm{~dB})$ on the $5 \%$ level of significance. The median squelch effect for both CI 1 and CI $2(0 \mathrm{~dB}$ and $1 \mathrm{~dB}$, respectively) was within the accepted range of $\leq 2 \mathrm{~dB}$ (Laszig et al., 2004; Litovsky et al., 2006; Van Deun et al., 2010) on a 5\% level of significance. The median summation benefits for both CI $1(0 \mathrm{~dB})$ and CI $2(2 \mathrm{~dB})$ added to $\mathrm{BiCI}$ in the NF condition was within the accepted value range of $\leq 6 \mathrm{~dB}$ (Litovsky et al., 2006; Wolfe et al., 2007; Eapen, Buss, Adunka, Pillsbury \& Buchman, 2009; Van Deun et al., 2010) at the 5\% level of significance. The median SRM benefit values were within the accepted range of 0 to $4 \mathrm{~dB}$ (Litovsky et al., 2006; Van Deun et al., 2010) only when the noise was directed to CI 1 at the $5 \%$ level of significance. An asymmetry between the values for noise directed to CI 1 versus CI 2 was observed, with greater values when the noise was presented to CI 1 . In addition to the SRM spatial benefit the improvement in speech perception in spatially distinct speech and noise from the addition of an ear with a better SNR was calculated. This was calculated as the difference between the SRT value for the left/right ear and the BiCI SRT value in the NL/ NR condition (Van Deun et al., 2010). The average value for adding the ear with the better SNR to CI 1 (thus the contribution of CI 2) (9 dB) is greater than the average value when the ear with the better SNR is added to CI 2 (thus the contribution of CI 1) $(5 \mathrm{~dB})$. The contribution of CI 2 therefore seems to be greater than the contribution of CI 1 for bilateral spatial benefit.

\section{Discussion \\ Speech-in-noise perception}

A bilateral benefit for speech-in-noise perception was found in the current study in the condition with noise directed to CI 1 , yet it was not statistically significant. The majority of participants $(64 \% ; 7 / 11)$ demonstrated benefit with an average benefit of $1.69 \mathrm{~dB}$ across the study sample. This improvement is significantly less than previously reported for simultaneously implanted adults, with an average bilateral benefit improvement of $5 \mathrm{~dB}$ (Cochlear Corporation Limited, 2005). The results are however comparable with previously reported bilateral benefit for sequentially implanted young adults ( $\leq 19$ years of age) of $0.49-4.8 \mathrm{~dB}$ in spatially separated speech and noise conditions (Galvin et al., 2010). With noise directed to CI 1 and noise to CI 2, 64\% and 36\% of participants achieved a speech-in-noise-perception bilateral benefit, respectively. This is presumably because they were better able to process the speech signal when they listened with both their implants, as the spatial separation of the speech and noise sources better enabled them to segregate the speech signal from the noise (Dunn, Noble, Tyler, Kordus, Gantz \& Haihong, 2010). The majority of participants (91\% for CI 1;

Table 5. Bilateral spatial benefits effects sizes

\begin{tabular}{|c|c|c|c|c|c|c|c|c|c|c|c|c|}
\hline Participant & $\begin{array}{l}\text { HS } 90^{\circ} \\
\text { CI } 1\end{array}$ & $\begin{array}{l}\text { HS } 90^{\circ} \\
\text { CI } 2\end{array}$ & $\begin{array}{l}\text { HS } 180^{\circ} \\
\text { CI } 1\end{array}$ & $\begin{array}{l}\text { HS } 180^{\circ} \\
\text { CI } 2\end{array}$ & $\begin{array}{l}\text { Summation: } \\
\text { With CI } 1 \\
\text { added }\end{array}$ & $\begin{array}{l}\text { Summation: } \\
\text { With CI } 2 \\
\text { added }\end{array}$ & $\begin{array}{l}\text { Squelch: } \\
\text { Noise on } \\
\text { CI } 1\end{array}$ & $\begin{array}{l}\text { Squelch: } \\
\text { Noise on } \\
\text { CI } 2\end{array}$ & $\begin{array}{l}\text { SRM: } \\
\text { Noise on } \\
\text { CI } 1\end{array}$ & $\begin{array}{l}\text { SRM: } \\
\text { Noise on } \\
\text { CI } 2\end{array}$ & $\begin{array}{l}\text { SNR: } \\
\text { Better ear } \\
\text { added to } \\
\text { CI } 1\end{array}$ & $\begin{array}{l}\text { SNR: } \\
\text { Better ear } \\
\text { added to } \\
\text { CI } 2\end{array}$ \\
\hline 1 & $0 \mathrm{~dB}$ & $1 \mathrm{~dB}$ & $4 \mathrm{~dB}$ & $11 \mathrm{~dB}$ & $0 \mathrm{~dB}$ & $2 \mathrm{~dB}$ & $-3 \mathrm{~dB}$ & $2 \mathrm{~dB}$ & $3 \mathrm{~dB}$ & $-5 \mathrm{~dB}$ & $10 \mathrm{~dB}$ & $5 \mathrm{~dB}$ \\
\hline 2 & $-6 \mathrm{~dB}$ & $-6 \mathrm{~dB}$ & $1 \mathrm{~dB}$ & $-1 \mathrm{~dB}$ & $0 \mathrm{~dB}$ & $0 \mathrm{~dB}$ & $0 \mathrm{~dB}$ & $-1 \mathrm{~dB}$ & $-5 \mathrm{~dB}$ & $-6 \mathrm{~dB}$ & $1 \mathrm{~dB}$ & $0 \mathrm{~dB}$ \\
\hline 3 & $-3 \mathrm{~dB}$ & $0 \mathrm{~dB}$ & $5 \mathrm{~dB}$ & $7 \mathrm{~dB}$ & $-3 \mathrm{~dB}$ & $6 \mathrm{~dB}$ & $5 \mathrm{~dB}$ & $6 \mathrm{~dB}$ & $9 \mathrm{~dB}$ & $-4 \mathrm{~dB}$ & $23 \mathrm{~dB}$ & $1 \mathrm{~dB}$ \\
\hline 4 & $-5 \mathrm{~dB}$ & $7 \mathrm{~dB}$ & $1 \mathrm{~dB}$ & $7 \mathrm{~dB}$ & $0 \mathrm{~dB}$ & $2 \mathrm{~dB}$ & $4 \mathrm{~dB}$ & $-1 \mathrm{~dB}$ & $6 \mathrm{~dB}$ & $-4 \mathrm{~dB}$ & $15 \mathrm{~dB}$ & $-4 \mathrm{~dB}$ \\
\hline 5 & $4 \mathrm{~dB}$ & $0 \mathrm{~dB}$ & $11 \mathrm{~dB}$ & $2 \mathrm{~dB}$ & $4 \mathrm{~dB}$ & $4 \mathrm{~dB}$ & $-1 \mathrm{~dB}$ & $7 \mathrm{~dB}$ & $2 \mathrm{~dB}$ & $0 \mathrm{~dB}$ & $12 \mathrm{~dB}$ & $6 \mathrm{~dB}$ \\
\hline 6 & $4 \mathrm{~dB}$ & $-4 \mathrm{~dB}$ & $9 \mathrm{~dB}$ & $2 \mathrm{~dB}$ & $0 \mathrm{~dB}$ & $0 \mathrm{~dB}$ & $-4 \mathrm{~dB}$ & $4 \mathrm{~dB}$ & $0 \mathrm{~dB}$ & $0 \mathrm{~dB}$ & $5 \mathrm{~dB}$ & $5 \mathrm{~dB}$ \\
\hline 7 & $9 \mathrm{~dB}$ & $2 \mathrm{~dB}$ & $10 \mathrm{~dB}$ & $6 \mathrm{~dB}$ & $2 \mathrm{~dB}$ & $-2 \mathrm{~dB}$ & $-9 \mathrm{~dB}$ & $-3 \mathrm{~dB}$ & $-3 \mathrm{~dB}$ & $3 \mathrm{~dB}$ & $-4 \mathrm{~dB}$ & $8 \mathrm{~dB}$ \\
\hline 8 & $0 \mathrm{~dB}$ & $11 \mathrm{~dB}$ & $1 \mathrm{~dB}$ & $17 \mathrm{~dB}$ & $5 \mathrm{~dB}$ & $6 \mathrm{~dB}$ & $0 \mathrm{~dB}$ & $0 \mathrm{~dB}$ & $6 \mathrm{~dB}$ & $-5 \mathrm{~dB}$ & $12 \mathrm{~dB}$ & $5 \mathrm{~dB}$ \\
\hline 9 & $-5 \mathrm{~dB}$ & $-2 \mathrm{~dB}$ & $1 \mathrm{~dB}$ & $3 \mathrm{~dB}$ & $0 \mathrm{~dB}$ & $0 \mathrm{~dB}$ & $10 \mathrm{~dB}$ & $1 \mathrm{~dB}$ & $-4 \mathrm{~dB}$ & $5 \mathrm{~dB}$ & $6 \mathrm{~dB}$ & $10 \mathrm{~dB}$ \\
\hline 10 & $5 \mathrm{~dB}$ & $-3 \mathrm{~dB}$ & $7 \mathrm{~dB}$ & $5 \mathrm{~dB}$ & $4 \mathrm{~dB}$ & $6 \mathrm{~dB}$ & $4 \mathrm{~dB}$ & $5 \mathrm{~dB}$ & $-2 \mathrm{~dB}$ & $3 \mathrm{~dB}$ & $5 \mathrm{~dB}$ & $15 \mathrm{~dB}$ \\
\hline 11 & $-6 \mathrm{~dB}$ & $-5 \mathrm{~dB}$ & $-2 \mathrm{~dB}$ & $1 \mathrm{~dB}$ & $-2 \mathrm{~dB}$ & $1 \mathrm{~dB}$ & $5 \mathrm{~dB}$ & $-1 \mathrm{~dB}$ & $-4 \mathrm{~dB}$ & $-1 \mathrm{~dB}$ & $1 \mathrm{~dB}$ & $3 \mathrm{~dB}$ \\
\hline Median & $0 \mathrm{~dB}$ & $0 \mathrm{~dB}$ & $4 \mathrm{~dB}^{*}$ & $5 \mathrm{~dB}^{*}$ & $0 \mathrm{~dB}^{\star}$ & $2 \mathrm{~dB}^{*}$ & $0 \mathrm{~dB}^{*}$ & $1 \mathrm{~dB}^{*}$ & $0 \mathrm{~dB}^{*}$ & $-1 \mathrm{~dB}$ & $9 \mathrm{~dB}$ & $5 \mathrm{~dB}$ \\
\hline
\end{tabular}


55\% for CI 2) demonstrated a performance advantage for the implant closest to the speech source compared with the implant closest to the noise source in unilateral listening conditions. This is known as a headshadow benefit and was found to be a robust and significant benefit for speech-in-noise perception for dichotic listening conditions (listening condition where the speech and noise signals are spatially separated) in the vast majority of participants. This suggests some degree of bilateral benefit for speech-in-noise perception for the delayed sequentially implanted users in the current study (Laszig et al., 2004).

In the diotic listening condition (listening condition where the speech and noise signals are spatially coincident) no significant bilateral benefit for speech in noise was found among sequentially implanted adults. A bilateral benefit for speech-in-noise perception was observed in only $36 \%$ of participants $(4 / 11)$ with the average benefit $(0.78 \mathrm{~dB})$ less than the bilateral benefit of $\geq 1.4 \mathrm{~dB}$ previously reported for simultaneously implanted users (Tyler et al., 2002; Cochlear Corporation Limited, 2005; Ramsden et al., 2005; Litvosky et al., 2006). Most participants (9/11) demonstrated some bilateral speech-in-noise-perception benefit in at least one of the dichotic and/or diotic listening conditions.

Compared with previous studies of bilateral implantation in adults the current findings indicate that more robust improvements in speech-innoise perception are typical of simultaneously implanted adult CI users than delayed sequentially implanted users (Tyler et al., 2002; Cochlear Corporation Limited, 2005; Ramsden et al., 2005; Litvosky et al., 2006). The concurrent stimulation of both peripheral and central auditory systems may lead to improved interaction between the ipsi- and contralateral auditory pathways and provide more robust processing of signals (Manrique et al., 2007). Simultaneously implanted listeners required an SNR of at least $6.8 \mathrm{~dB}$ to achieve speech perception after 1 year, decreasing to $1.8 \mathrm{~dB}$ after 4 years of bilateral simultaneous implantation (Eapen et al., 2009). The latter SNR is significantly lower than the SNR values recorded for delayed sequentially implanted adults in this study (average SNR: $18.83 \mathrm{~dB}$ ) despite most participants (6/11) having had bilateral experience of more than 4 years (Table 2).

The majority (9/11) of participants in the current study are delayed sequentially implanted users; the extent of bilateral benefits are limited further as a result of a lack of concurrent stimulation in auditory pathways compared with simultaneously and/or sequentially implanted adults (Manrique et al., 2007). According to Litovksy et al. (2006, 2009) a longer experience with $\mathrm{BiCI}$ use may be related to improvements in speech understanding in noise. A performance advantage is evident for 2 - 3 years after implantation after which a decline may be evident as users reach their performance plateau (Manrique et al., 2007). Since participants in the current study were evaluated at least 2 years post CI 2 they may already have reached their performance plateau phase, in contrast to benefits reported in previous studies that are typically measured between 3 and 9 months post implantation (Cochlear Corporation Limited, 2005; Galvin et al., 2010).

\section{Bilateral spatial benefits}

The head-shadow effect at $180^{\circ}$ was found to be the strongest and most robust bilateral spatial benefit for delayed sequentially implanted adults in this study. It was attained on at least 1 of the 2 unilateral CI comparisons for nearly all participants (9/11). Furthermore, the median values of $4 \mathrm{~dB}$ for the contribution from CI 1 and $5 \mathrm{~dB}$ for the contribution from CI 2 to the head-shadow effect at $180^{\circ}$ was well within the accepted range of $3 \mathrm{~dB}$ except at $90^{\circ}$ (Laszig et al., 2004; Litovsky et al., 2006; Van Deun et al., 2010). Results suggest that the greater the spatial separation between the speech signal and the noise source, the greater the head-shadow effect for the delayed sequentially implanted adults with bilateral benefits comparable with those reported in simultaneous and sequentially implanted adults(Laszig et al., 2004; Litovsky et al., 2006; Van Deun et al., 2010).

The squelch effect in general is small even in normal-hearing listeners where it is in the order of $3 \mathrm{~dB}$ (Eapen et al., 2009). It has been reported in only a few previous studies investigating bilateral benefit in adult CI users (Laszig et al., 2004; Eapen et al., 2009). Current reports demonstrate a benefit of $2 \mathrm{~dB}$ and even zero or negative effects in sequentially and simultaneously implanted adults (Laszig et al., 2004; Litovsky et al., 2006; Van Deun et al., 2010). The majority of participants in the current study (55\% for CI $1 ; 64 \%$ for CI 2 ) also presented with a squelch effect within the accepted benefit cut-off of $\leq 2$ $\mathrm{dB}$ which is comparable with those previously reported for sequentially and simultaneously implanted adults (Laszig et al., 2004; Litovsky et al., 2006; Van Deun et al., 2010).

Four participants obtained a negative squelch effect during the condition with noise on CI 1 (participants 1, 5, 6 and 7) and when the noise was directed to CI 2 (participants 2, 4, 7 and 11). When the noise was on CI 1 , however, and this implant was added in the bilateral test, the range of negative values was greater (ranging from $-1 \mathrm{~dB}$ to $-9 \mathrm{~dB}$ ) than the range of negative values for when the noise was directed to $\mathrm{CI}$ 2 (ranging from $-1 \mathrm{~dB}$ to $-3 \mathrm{~dB}$ ). This might be explained by the fact that using the $\mathrm{CI}$ ipsilateral to the noise source resulted in degradation of the SNR at that ear (Van Deun et al., 2010). The decrease in SNR might be more significant when the noise is near the CI 1 , which was the inferior functioning ear in the condition with noise directed to the CI 1 for participants 1, 5, and 6(Van Deun et al., 2010). Furthermore, the negative squelch effect values obtained by participants $1,2,4,5$, 6, 7 and 11 may also be attributed to distorted timing cues because of the lack of integration between the processing of the two processors (Ramsden et al., 2005).

All participants demonstrated a significant bilateral spatial benefit $(p<0.05)$ for summation when CI 1 and CI 2 were both used to listen in diotic conditions. The results correspond with previous reports on bilateral sequential and simultaneous adult CI users that demonstrated a summation benefit of up to $6 \mathrm{~dB}$ and/or no effect or negative effects (Litovsky et al., 2006; Wolfe et al., 2007; Eapen et al., 2009; Van Deun et al., 2010).

SRM values of $0 \mathrm{~dB}$ up to $4 \mathrm{~dB}$ for sequentially and simultaneously implanted adults were reported in previous studies (Litovsky et al., 2006; Van Deun et al., 2010). Only in the noise directed to CI 1 condition did delayed sequentially implanted users' median SRM benefit (median: 0 $\mathrm{dB})$ correspond significantly $(p<0.05)$ with the reported value range in simultaneously and sequentially implanted adults. An asymmetry was however observed with the SRM[B] values indicating greater values when changing the noise to the $\mathrm{CI} 1$. Therefore, it may be assumed that the majority of participants performed better with their CI 2 relative to their CI 1 for speech-in-noise perception. The improvement in speech perception in spatially distinct speech and noise from adding the ear with a better SNR was calculated in support of the SRM. The average value for adding the SNR better ear to CI 1, thus the contribution of CI 2, was greater than the average value when the SNR better ear is added to CI 2 (thus the contribution of CI 1). Therefore, this may further denote the superior contribution of CI 2 for bilateral benefit during speech perception in spatially separated speech and noise for the delayed sequentially implanted adults in this study.

\section{Conclusion}

A bilateral benefit for speech-perception-in-noise abilities was noted in delayed sequentially implanted adults. However, statistically this was not significant. The delayed sequentially implanted users' head-shadow effect at $180^{\circ}$, squelch effect, and summation effect for both CI 1 and CI 2 corresponded significantly $(p<0.05)$ with previously reported cutoff normative values for bilateral spatial benefits in simultaneously and sequentially implanted adults. Delayed sequentially implanted adults may achieve some bilateral benefit even after many years of unilateral implant use. Yet, the extent of the bilateral benefit is less robust than reported for simultaneous and/or sequentially implanted adults (Tyler et al., 2002; Cochlear Corporation Limited, 2005; Ramsden et al., 2005; Litovsky et al., 2006). Most participants (9/11) attained some bilateral speech-in-noise-perception benefit in at least one of the dichotic and/ or diotic listening conditions. This underscores the importance of understanding the extent of these abilities, as they play an essential role 
in the rehabilitation of delayed sequential CI users. A key benefit of delayed sequential bilateral implantation appears to be related to the advantageous aspect of having hearing on both sides so that the ear with the more favourable environmental SNR is always available. Outcomes for these delayed sequentially implanted adults provide an indication of the bilateral benefit which may still be attainable after the official cut-off interval of more than 2 years for the CI 2 is exceeded.

\section{References}

Alpiner, J. G., \& McCarthy, P. A. (2000). Rehabilitative audiology: Children and adults. $3^{\text {rd }}$ Ed. Philadelphia: Lippincott Williams \& Wilkins.

Balkany, T., Hodges, A., Telischi, F., Hoffman, R., Madell, J., Parisier, S., Gantz, B., Tyler, R., \& Peters, R. (2008) William House Cochlear Implant Study Group: Position Statement on Bilateral Cochlear Implantation. Otology ơ Neurotology, 29(2), 107-108.

Cochlear Corporation Limited. Candidacy Criteria for Children and Adults (n.d.). Retrieved on 26 February 2008 from http://www.cochlear.com.

Cochlear Corporation Limited. (2005). Outcomes using bilateral cochlear implants in adults. [Brochure]. Australia. Retrieved on 12 November 2012 from: http://sites.cochlear.com/binaural/sites/default/files/outcomes_using_bilateral.pd

Dunn, C. C., Noble, W. Tyler, R. S., Kordus, M., Gantz, B. J. \& Haihong, J. (2010). Bilateral and unilateral cochlear implant users compared on speech perception in noise. Ear and Hearing 31(2), 296-298. doi:10.1097/ AUD.0b013e3181c12383

Eapen, R. J., Buss, E., Adunka, M. C., Pillsbury III, H. C., \& Buchman, C. A. (2009). Hearing-in-noise benefits after bilateral simultaneous cochlear implantation continue to improve 4 years after implantation. Otology e Neurotology, 30, 153-159. doi:10.1097/MAO.0b013e3181925025

Field, A. (2005). Discovering statistics using SPSS. London: Sage Publications.

Galvin, K. L., Hughes, K. C., \& Mok, M. (2010). Can adolescents and young adults with prelingual hearing loss benefit from a second, sequential cochlear implant? International Journal of Audiology, 49(5), 368-377. benefit from a second, sequenti
doi:10.3109/14992020903470767

Gantz, B. J., Tyler, R. S., Rubenstein, J. T. Wolaver A., Lowder M., Abbas, P., Brown, C., Hughes, M. \& Preece, J. P. (2002). Binaural cochlear implants placed during the same operation. Otology \& Neurotology, 23,169-180. doi:10.1097/00129492-200203000-00012

Harrel, R. W. (2002). Puretone Evaluation. In J. Katz (Ed.), Handbook of clinical audiology. (5 $5^{\text {th }}$ ed., pp. 71-87). Philadelphia: Lippincott Williams \& Wilkins.

Hughes, M. L., Van der Werf, K. R., Brown, C. J., Abbas, P. J., Kelsay, D. M. R., Teagle, H. F. B., \& Lowder, M. W. (2001). Longitudinal study of electrode impedance, electrically evoked compound action potential and behavioral measures in nucleus 24 cochlear implant users. Ear and Hearing, 22(6): 471-486. doi:10.1097/00003446200112000-00004

Laszig, R., Aschendorff, A., Stecker, M., Müller-Deile J, Maune S, Dillier N, Weber B, Hey M, Begall K, Lenarz T, Battmer RD, Böhm M, Steffens T, Strutz J, Linder T, Probst R, Allum J, Westhofen M, Doering W. (2004). Benefits of bilateral electrical stimulation with the nucleus cochlear implant in adults: 6-month postoperative results. Otology \& Neurotology, 25 (6), 958-968. doi:10.1097/00129492-200411000-00016

Leedy, P. D., \& Ormrod. J. E. (2005). Practical research: Planning and design. $8^{\text {th }}$ ed. Princeton, N.C.: Merill Publishing Company

Litovsky, R. Y., Parkinson, A., Arcaroli, J., \& Arcaroli, J. (2009). Spatial hearing and speech intelligibility in bilateral cochlear implant users. Ear and Hearing, 30(4), 419-431. doi:10.1097/AUD.0b013e3181a165be
Litovsky, R. Y., Parkinson, A., Arcaroli, J., Peters, R., Lake, J., Johnstone, P., \& Yu, G. (2004). Bilateral cochlear implants in adults and children. Archives of Otolaryngology - Head and Neck Surgery, 130(5), 648-655. doi:10.1001/archotol.130.5.648

Litovsky, R. Y., Parkinson, A., Arcaroli, J., \& Sammeth, C. (2006). Simultaneous bilateral cochlear implantation in adults: A multicenter clinical study. Ear and Hearing, 27(6), 714-731. doi:10.1097/01. aud.0000246816.50820.42

Lustig, R. L., \& Wackym, P. A. (2005). Bilateral cochlear implantation. Operative Techinques in Otolaryngoloy - Head and Neck Surgery, 16(2), 125-130. doi:10.1016/j.otot.2005.04.003

Manrique, M., Huarte, A., Valdivieso, A., \& Pérez, B. (2007). Bilateral sequential implantation in children. Audiological Medicine, 5(4), 224-231. doi:10.1080/16513860701705173

Miller, I., \& Miller, M. (2004). John E. Freund's mathematical statistics with applications. London: Pearson Prentice Hall. Moore, J. A., \& Teagle, H. F. B. (2002). An introduction to cochlear implant technology, activation, and programming. Language, Speech, and Hearing Services in Schools, 33, 156-161. doi:10.1044/0161$1461(2002 / 013)$

Muller, A. M. U., \& De Stadler, L. (1987). CID Sinne Afrikaanse Vertaling. Unpublished. University of Stellenbosch, Cape Town, South Africa.

Neuman, A. C., Haravon, A., Sislian, N., \& Waltzman, S. B. (2007). Sound-direction identification with bilateral cochlear implants. Ear and Hearing, 28(1), 73-82. doi:10.1097/01.aud.0000249910.80803.b9

Peters, B. J., Litovsky, R., Parkinson, A., \& Lake, J. (2007). Importance of age and postimplantation experience on speech perception measures in children with sequential bilateral cochlear implants. Otology \& Neurotology, 28, 649-657. doi:10.1097/01.mao.0000281807.89938.60

Ramsden, R., Greenham, P., O’Driscoll, M., Mawman, D., Proops, D., Craddock, L., et al. (2005). Evaluation of bilaterally implanted adult subjects with the Nucleus 24 Cochlear Implant System. Otology \& Neurotology, 25(6), 988-998. doi:10.1097/01.mao.0000185075.58199.22

Schön, F., Müller, J., \& Helms, J. (2002). Speech reception thresholds obtained in a symmetrical four-loudspeaker arrangement from bilateral users of MED-EL cochlear implants. Otology \& Neurotology, 23, 710-714. doi:10.1097/00129492-200209000-00018

Steyn, A. G. W., Smit, C. F., Du Toit, S. H. C., \& Strasheim, C. (2003). Modern statistics in practice. Pretoria: Van Schaik.

Teoh, S. W., Pisoni, D. B., \& Miyamoto, R. T. (2004). Cochlear implantation in adults with prelingual deafness. Part 1. Clinical results. The Laryngoscope, 114(9), 1536-1540. doi:10.1097/00005537-200409000-00006

Tyler, R. S., Dunn, C. C., Witt, S. A., \& Noble, W. G. (2007). Speech perception and localization with adults with bilateral sequential cochlear implants. Ear and Hearing, 28(2) Supplement, 86 - 90. doi:10.1097/ AUD.0b013e31803153e2

Tyler, R. S., Gantz, B. J., Rubinstein, J. T. Wilson B. S., Parkinson A. J., Wolaver A., Preece J. P., Witt S., Lowder M. W. (2002). Three-month results with bilateral cochlear implants. Ear and Hearing, 23(1) Supplement, 80-89. doi:10.1097/00003446-200202001-00010

Van Deun, L., van Wieringen, A., \& Wouters J. (2010). Spatial speech perception benefits in young children with normal hearing and cochlear implants. Ear and Hearing, 31(5), 702-713.

Wilber, L. A. (2002). Calibration: Puretone, speech and noise signals. In J. Katz (Ed.), Handbook of clinical audiology (5 $5^{\text {th }}$ ed., pp. 50-67). Philadelphia: Lippincott Williams \& Wilkins.

Wolfe, J., Baker, S., Caraway, T., Kasulis H., Mears A., Smith J., Swim L., Wood M. (2007). 1-year postactivation results for sequentially implanted bilateral cochlear implant users. Otology \& Neurotology, 28(5), 589-596. doi:10.1097/ MAO.0b013e318067bd24

Wolfe, J., \& Schafer, E. C. (2010). Effects of accessory-mixing ration on performance with personal FM and cochlear implants. In: C. DeConde Johnson, D. E. Lewis, H. E. Mülder \& L. M. Thibodeau (Eds.), Achieving clear communication employing sound solutions - 2008: Proceedings of the First International Virtual Conference on FM (pp. 146-153). Stäfa, Switzerland: Phonak AG. 